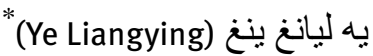

\title{
تعليم اللغة العربية في الجامعات الصينية
}

\section{Arabic Language Teaching in Chinese Universities: Inheritance and Innovation}

https://doi.org/10.1515/caas-2021-2003

تاريخ النشر:30-82021

الملخص: اللغة العربية هي اللغة القومية المشتركة للأمة العربية، وأحد أهم مقومات الهوية الخاصة بها، و هي أيضا

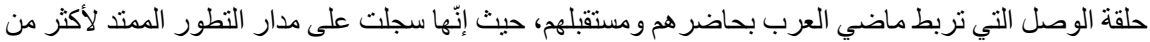
1600 عام التغير ات التاريخية للأمة العربية، وجسّدت شخصيتها وخصائصها، وحافظت على على ثقافتها وحضارتها عبر الزمان.

تعتبر اللغة العربية من أقدم اللغات الأجنبية التي نمَّ تدريسها في الصبن، ولعبت دورًا محوريًّا في تعزيز

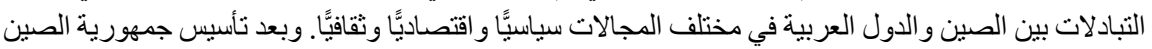

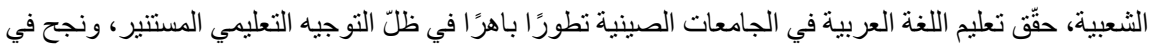

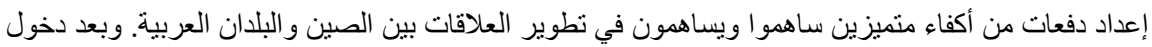

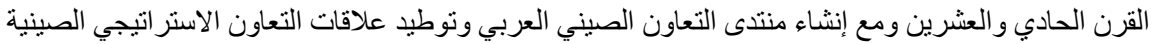

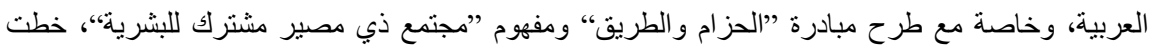

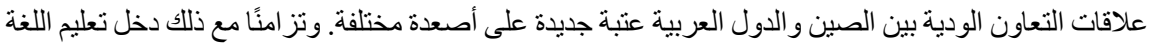
العربية في الجامعات الصينية مسار التطور السريع، وحقق نتائج لافتة. الكلمات مفتاحية: الجامعات الصينية؛ تعليم اللغة العربية؛ البحوث الأكاديمية؛ مسار التطور

Abstract: The Arabic language is the common official language for the Arab nation, and one of the most important components of its identity, and it is also the link that connects the past of the Arabs with their present and their future, as it recorded the historical changes of the Arab nation over the course of the development extending for more than 1,600 years, and embodied its characteristics and preserved its culture and civilization through time.

Arabic is one of the oldest foreign languages taught in China, and it played a pivotal role in promoting exchanges between China and Arab countries in various fields, politically, economically and culturally. After the founding of the People's

yeliangying@bfsu.edu.cn يله ليانغ ينغ، جامعة الدراسات الأجنبية بيكين، بكين، الصين، *

כ Open Access. (ب) يه ليانغ ينغ 2021 , published by De Gruyter.

(c) BY This work is licensed under the Creative Commons Attribution-NonCommercial-NoDerivatives 4.0 License. 
Republic of China, Arabic language teaching in Chinese universities achieved a remarkable development under the enlightened educational guidance, and succeeded in preparing batches of distinguished people who contributed and are contributing to the development of relations between Arab countries and China. After entering the 21st century and with the establishment of the China-Arab States Cooperation Forum and the consolidation of Sino-Arab strategic cooperation relations, especially with the launch of the Belt and Road Initiative and the concept of "One Community with a Shared Future for Mankind", the cooperation relations between China and the Arab countries have reached a new threshold on various levels. Simultaneously, Arabic teaching in Chinese universities has entered the path of rapid development and achieved unparalleled remarkable results.

Keywords: Chinese universities; Arabic teaching; academic research; development path

\section{1 المقدمة}

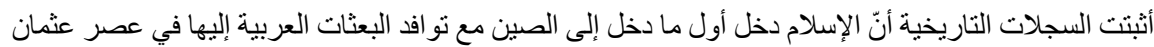

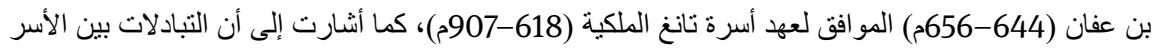

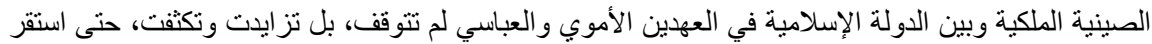

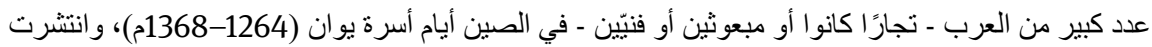

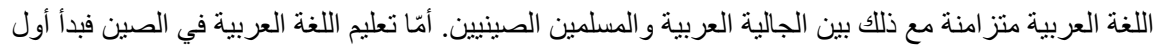

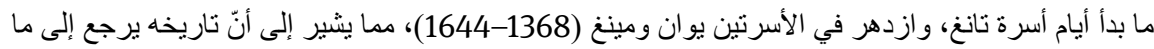

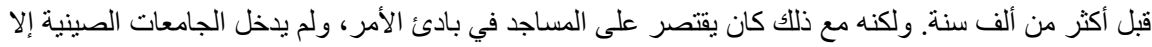
قبيل تأسيس جمهورية الصين الشعبية.

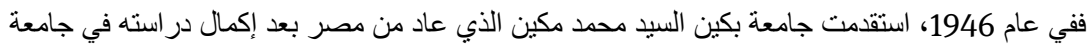

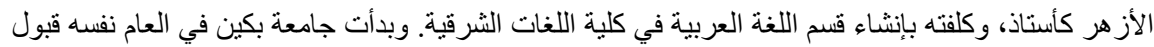

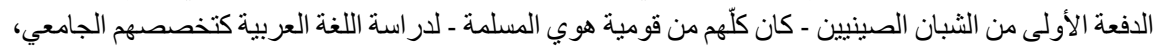

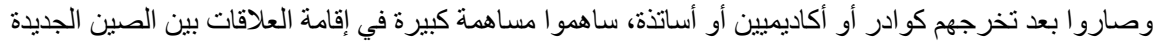

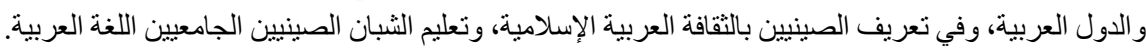
و هكذا تمّ إدر اج تخصص اللغة العربية لأول مرة إلى منظومة التعليم العالي في الصين.

\section{2 فترة التطور النشط: من 1949 إلى 1966}

بعد نضالات شاقة مريرة استمرت لـ28 سنة، أفلح الشعب الصيني تحت قيادة الحزب الثيو عي الصيني في تأسيس

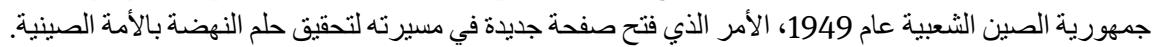
وولجت الصين على إثر ذلك مرحلة التنمية المستقرة التي طالت مختلف الأصعدة، بيد أن الدول الغربية - و على الصى 
ر أسها الو لايات المتحدة - كانت تتبنى سياسة التطويق و الاحتو اء ضدّ الصين الجديدة. وسعيًا إلى توسيع آفاق التعاون

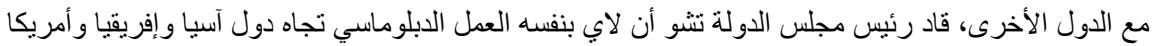

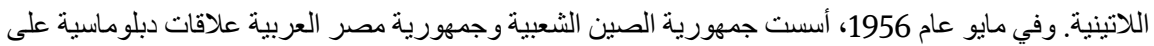
مستوى السفراء، مما جعل مصر أول دولة عربية وشرق أو أوسطية وإفريقية تقيم علاقات دبلوماسية مع الصين.

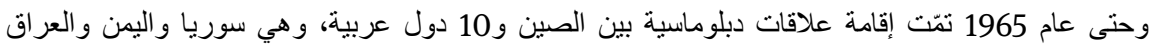

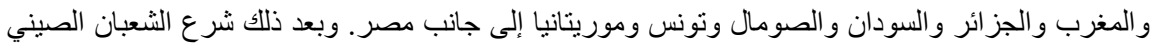

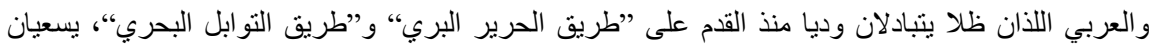
للمضي قدما يدا بيد في سبيل تحقيق النهضية للأمتين العظيمتين.

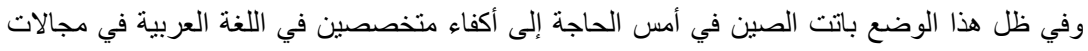

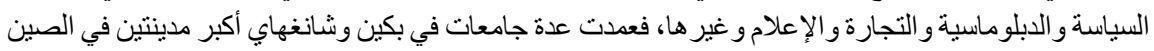

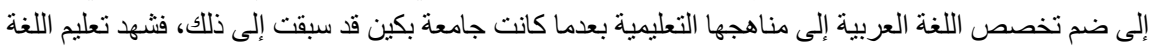

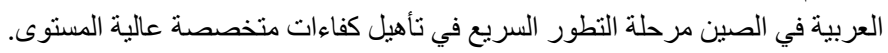

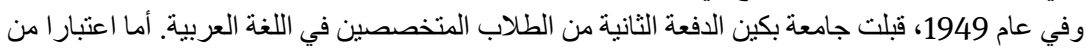

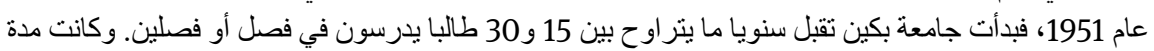

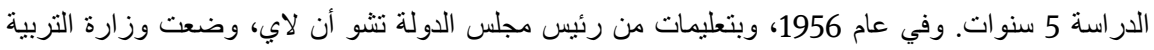

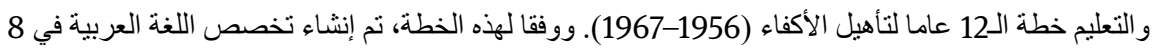

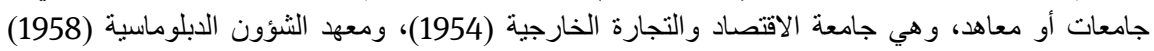

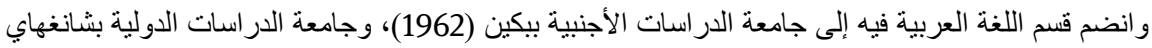

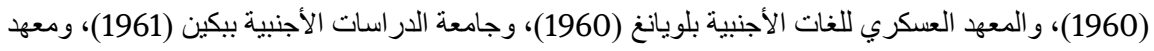
التجارة الخارجية بشانغهاي (1961) و وانضم قسم اللغة العربية فيه إلى جامعة الدر اسات الدات الدولية بشانغهابي لاحقا)،

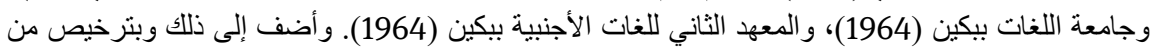

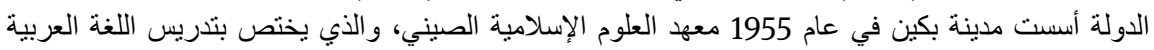

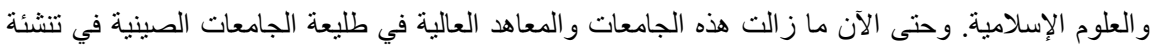

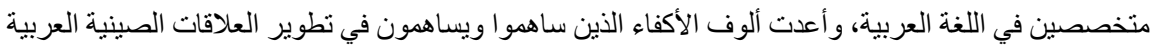

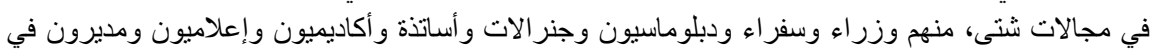
الشركات و إلخ. و الأساتذة الذين أنشؤوا تخصص اللغة العربية في الجامعات الصينية، منهم محمد مكين ونا جونغ وليو لين

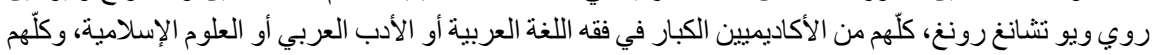

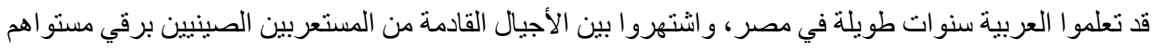

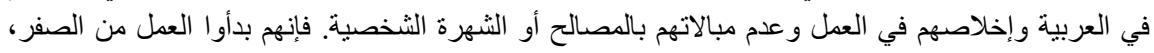

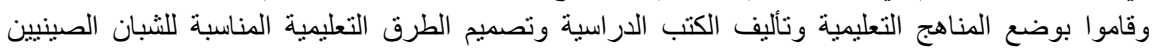

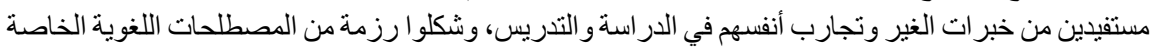

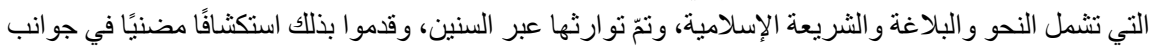

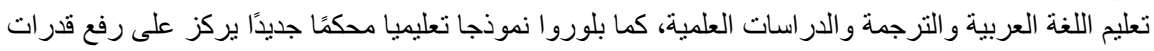

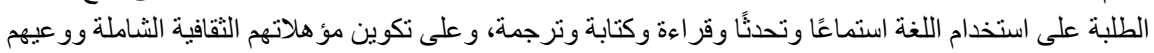

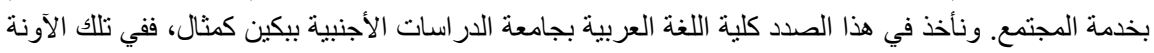

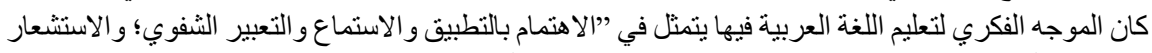

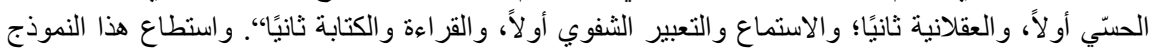

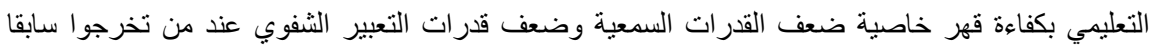
معتمدين على النموذج التقليدي. 
ومنذ نم إدر اج تخصص اللغة العربية في المنظومة التعليمية العالية في الصين، حظيت الأعمال المتعلقة

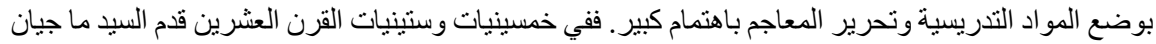

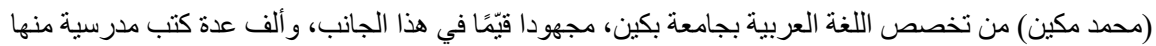

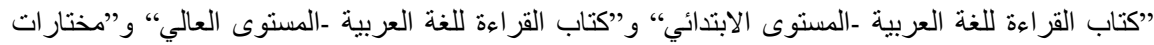

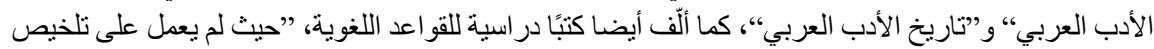

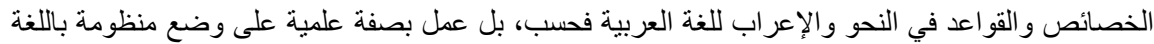

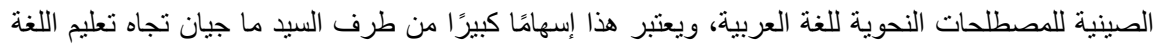

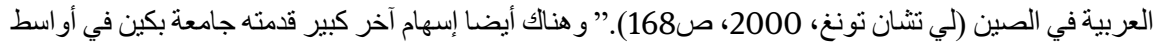

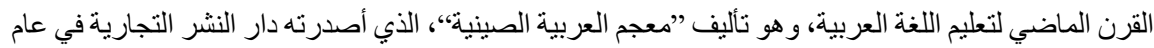

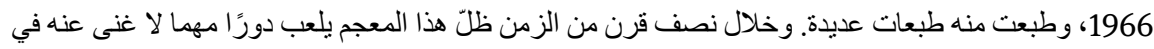

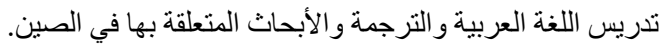

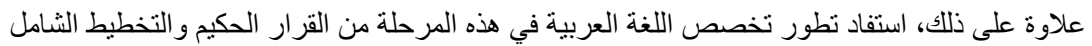

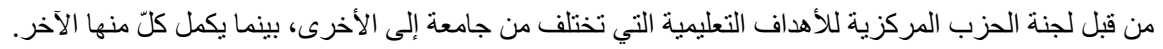

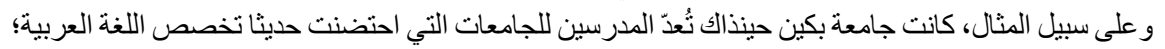

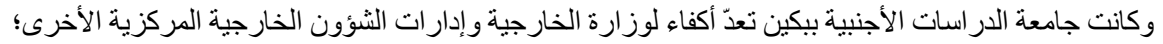

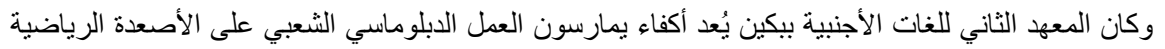

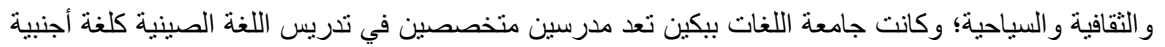

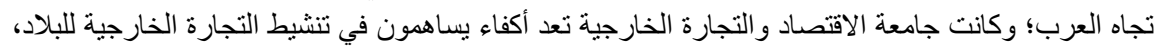

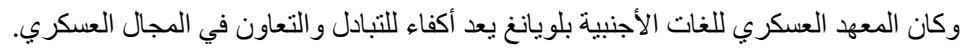

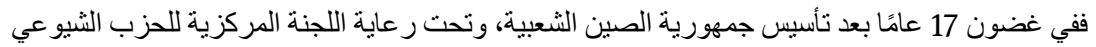

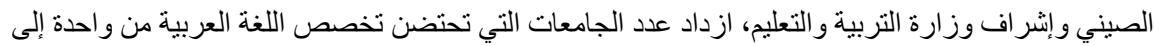

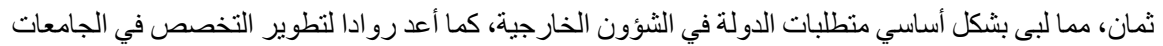

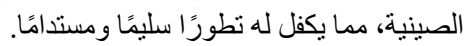

\section{3 فترة الانحطاط: من 1966 إلى 1976}

في عام 1966، عندما كان تعليم اللغة العربية في الجامعات الصينية يشهد تطورًا نشطًا، بدأت "الثورة الثقافية

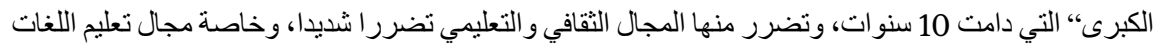

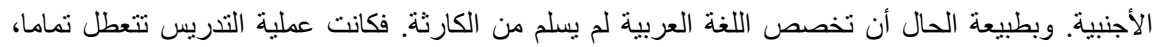

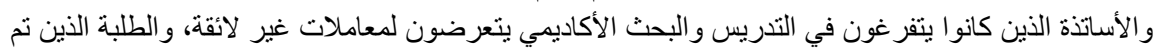

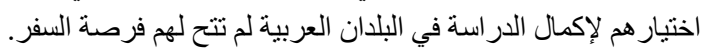

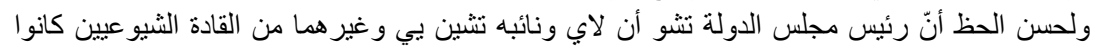

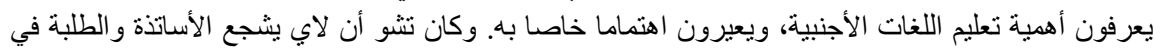

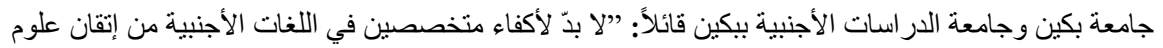

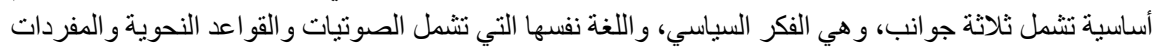

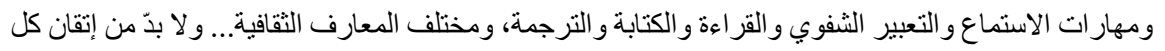

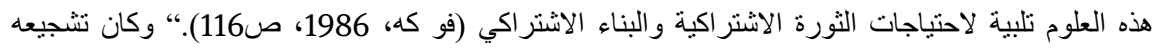

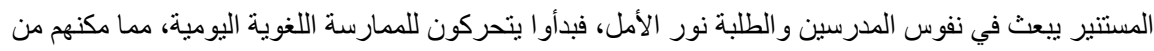
مباشرة العمل فور تخرجهم من الجامعة. 


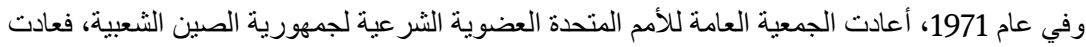

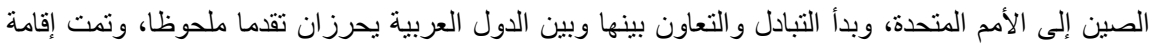

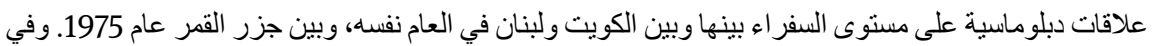

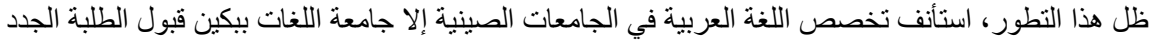

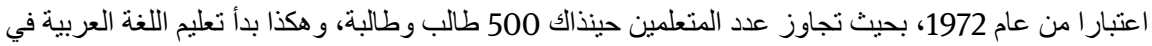

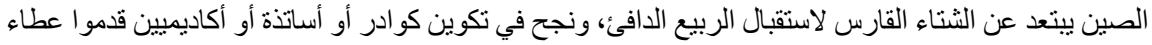

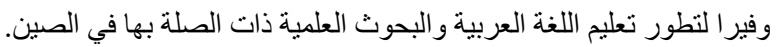

\section{4 فترة الازدهار: من 1978 إلى 2003}

في عام 1978، تم تثكيل الجيل الثاني من القيادة المركزية للحزب الثيوعي الصيني التي اتخذت السيد دنغ شياو

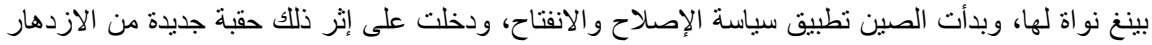

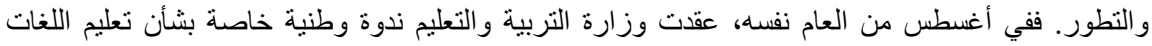

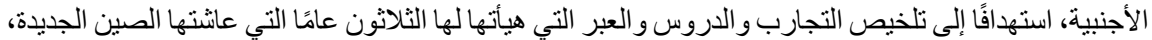

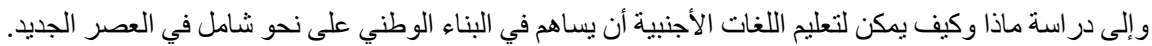

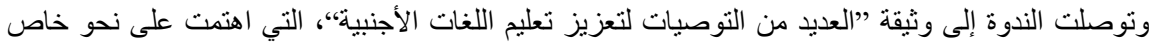

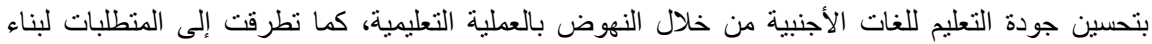

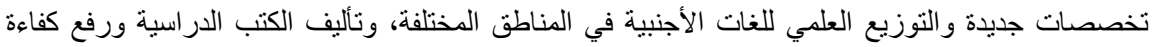

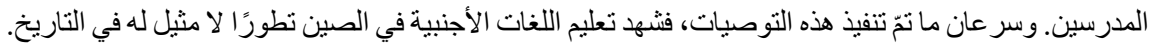

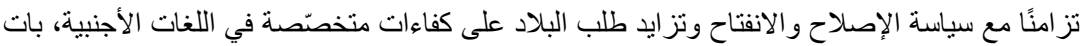

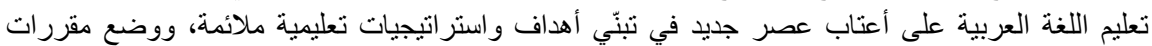

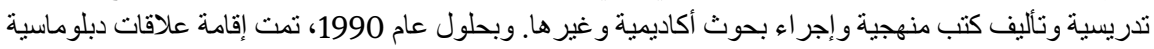

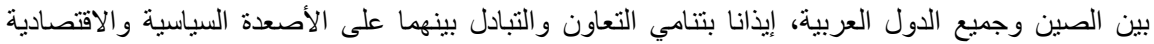

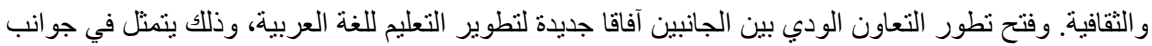

مختلفة:

\section{4 تثكيل لجان توجيهية لتعزيز التخطيط العام لقضية التعليم للغة العربية}

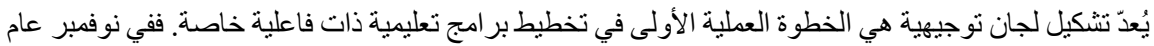

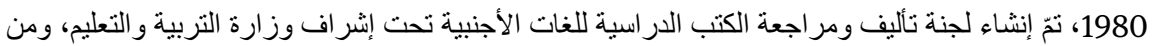

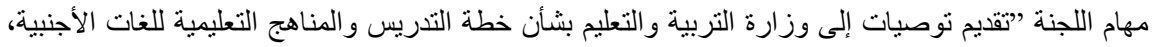

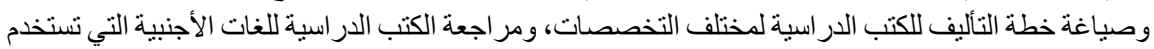

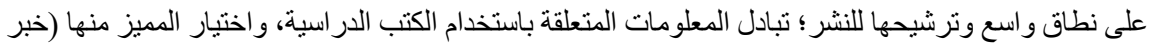

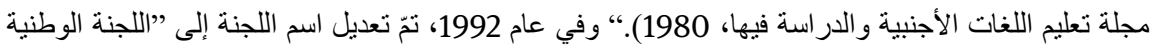

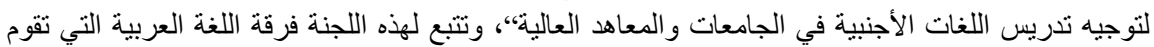

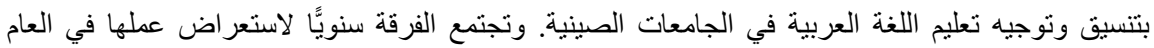

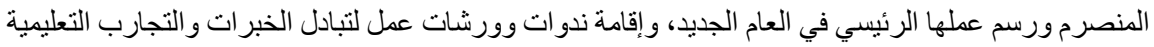

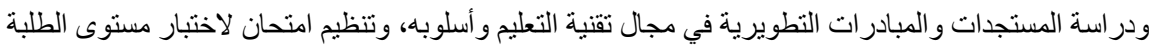


من الدرجة الر ابعة، مما يقدم إرشادات قيمة لتطور التخصص ورفع كفاءة المدرسين.

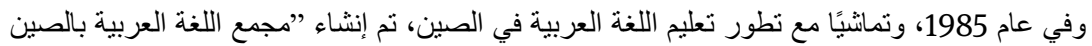

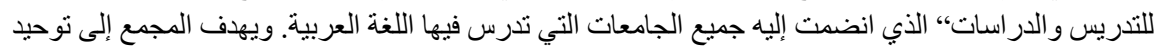

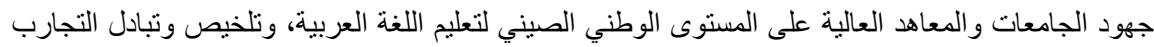

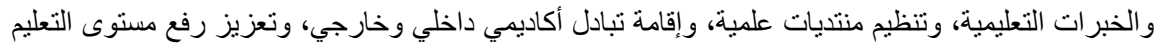

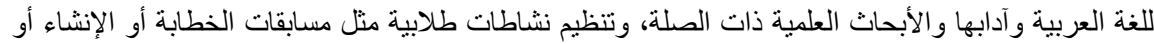

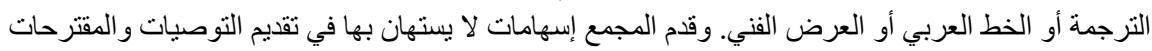

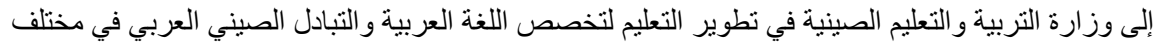

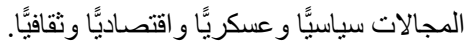

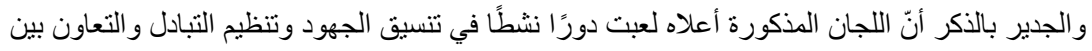
الجامعات، وفي التخطبط الثامل لتعليم اللغة العربية.

\section{4 تبني "منهج تعليم اللغة العربية في الجامعات الصينية، لضبط التدريس}

منذ تأسيس الصين الجديدة، اكتسب تعليم اللغة العربية في الجامعات الصينية خبرات وافرة من خلال الممارسات

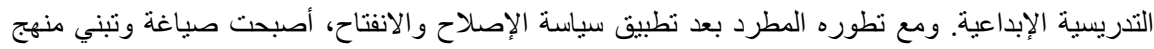

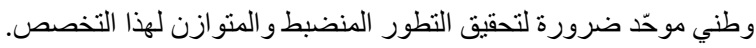

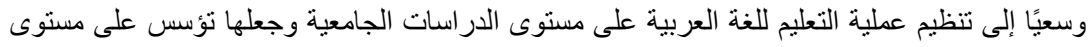

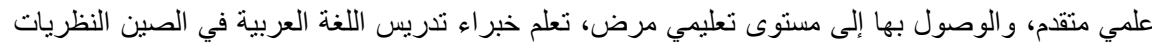

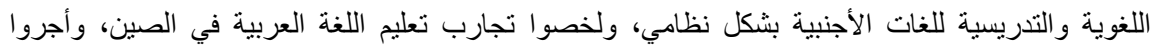

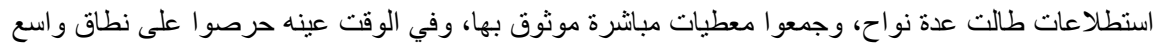

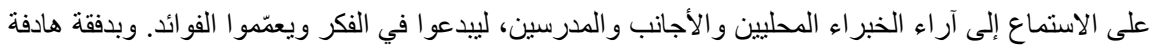

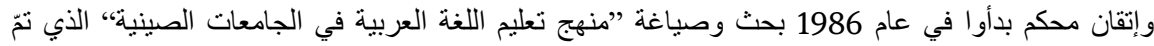

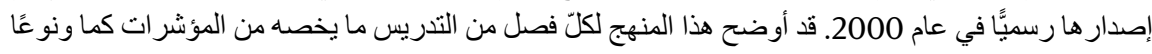

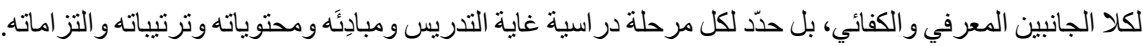

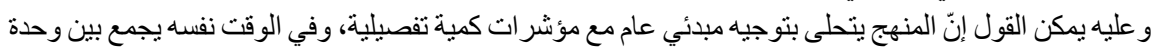

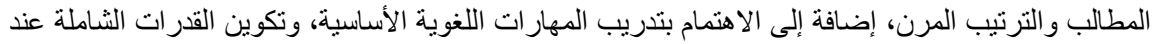

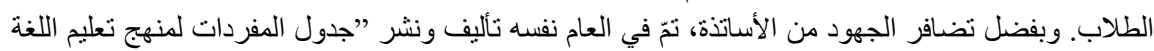
العربية في الجامعات الصينية،، الذي يضم 9000 مفردة و 3000 عبارة اصطلاحية، مما جعله مرجعًا معتمدًا

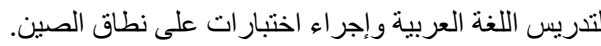

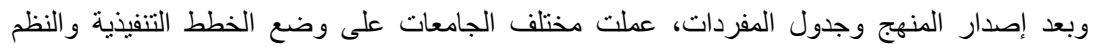

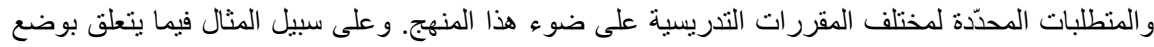

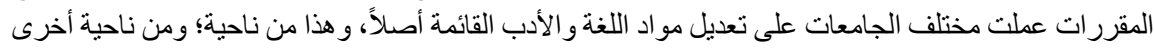

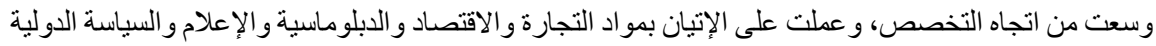

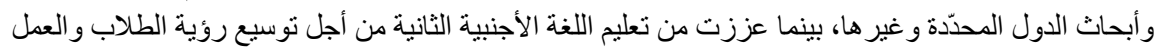

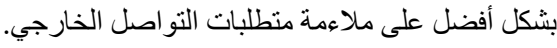

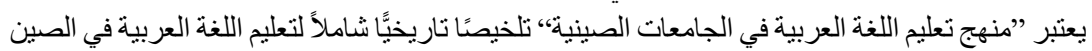

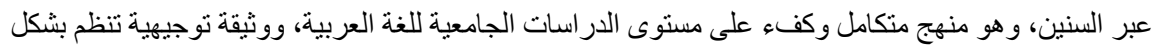
علمي نشاطات التعليم في مختلف الجامعات. 


\section{4 زيادة مقاعد القبول للطلبة وتظوير الاراسات العليا}

مع زيادة حجم التبادلات بين الصين والدول العربية في مختلف المجالات، شهدت سوق التوظيف للأكفاء

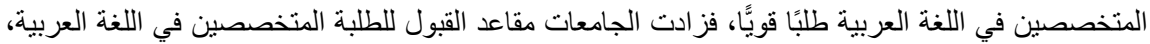
وذللك تتمثل في نواح: 1) تبادرت خمس جامعات أخرى إلى فتح تخصص أخص اللغة العربية، وهي جامعة القوميات في شمال غربي

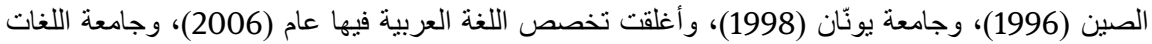

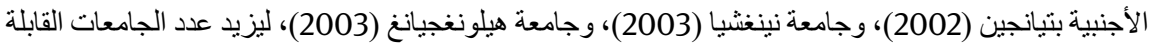

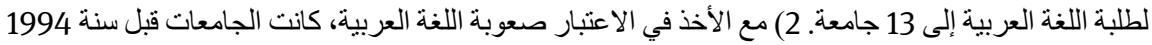

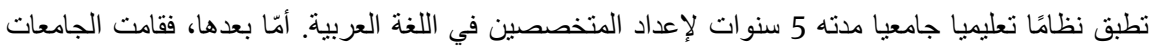

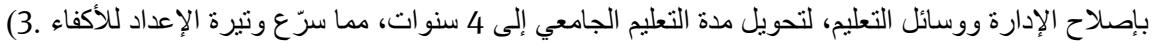

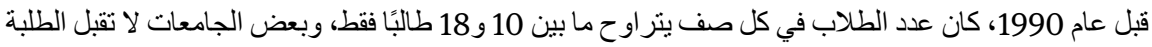

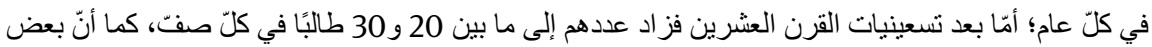

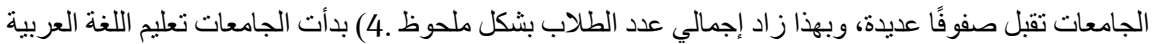

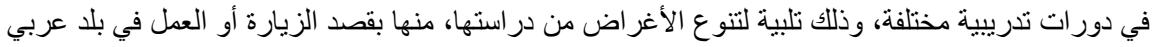

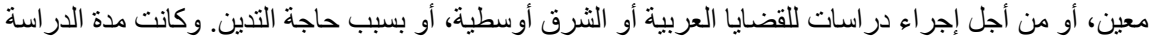

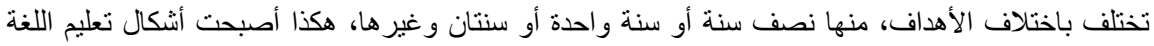

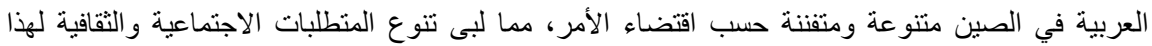

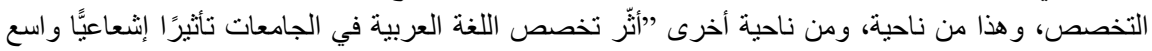

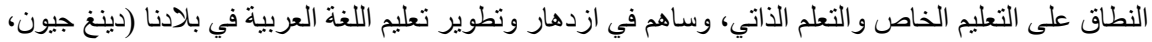

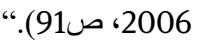

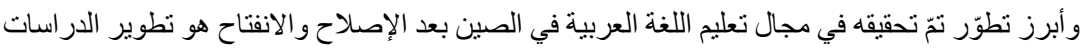

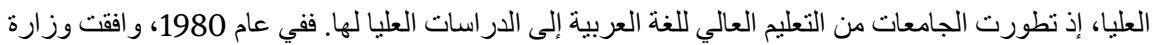

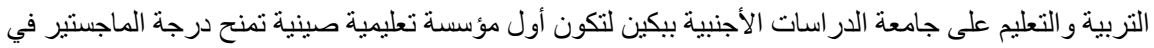

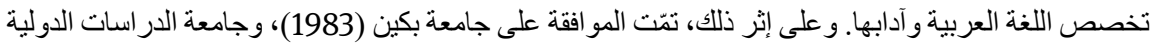

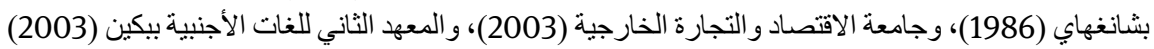

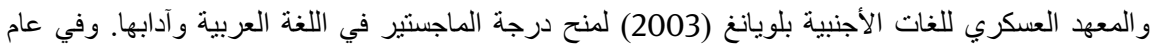

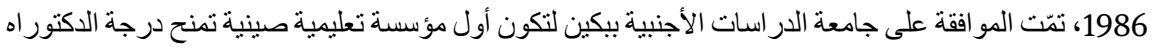

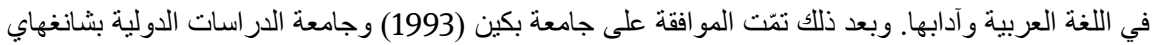

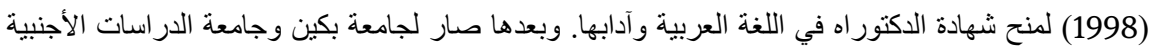

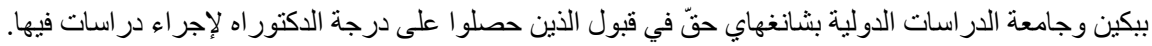

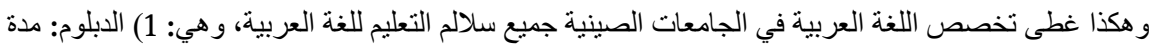

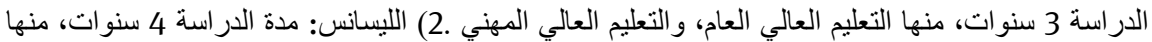

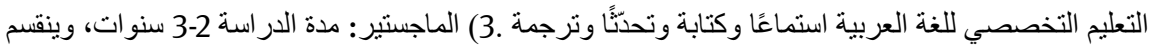

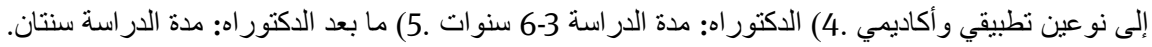

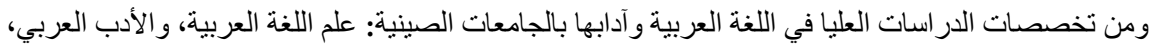

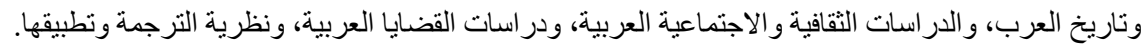

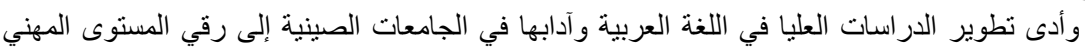

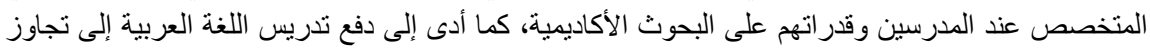

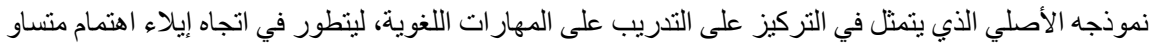


للمهار ات اللغوية واستيعاب المعارف وتتمية القدر ات على البحوث العلمية.

\section{4 إيلاء اهتمام بتأليف الكتب الدراسية وإصلاح المحتوى التعليمي}

تلبية لاحتياجات سوق العمل وضرورة رفع مستوى الخريجين، حرصت الجامعات على تطبيق أحدث أساليب

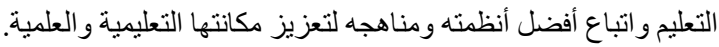

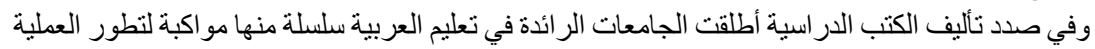
التعليمية، و على سبيل المثال أطلقت جامعة الدر اسات الأجنبية ببكين في الفترة ما بين عامي

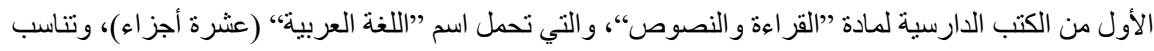

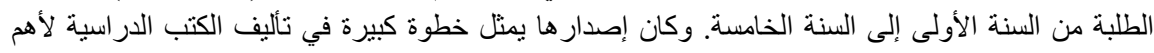

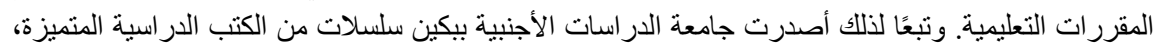

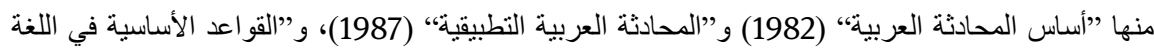

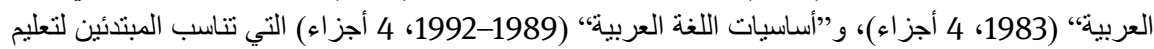
العربية. كما أصدرت جامعة الدراسات الدولية بشانغهاي ”الترجمة الثفوية بين العربية والصينية، التربة، (1987) و "در اسة الترجمة بين العربية و الصينية ـ نظريا وتطبيقيا، (1991) و غير ها من الكتب الدراسية التي شهدت إقبالاً

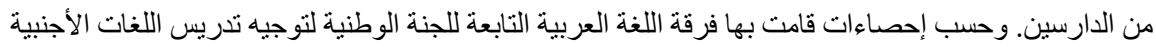

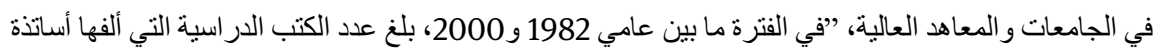

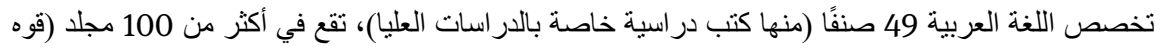

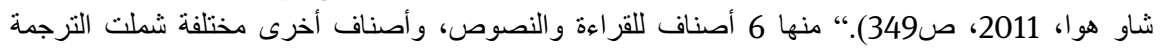

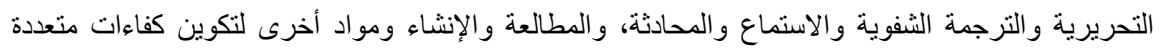

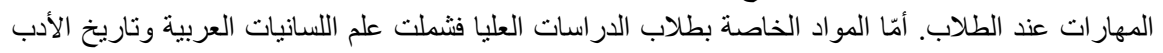

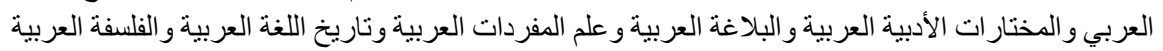

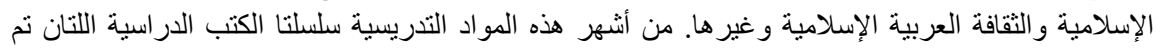

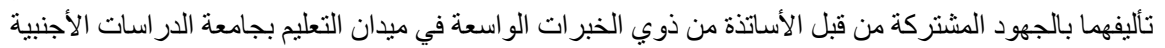

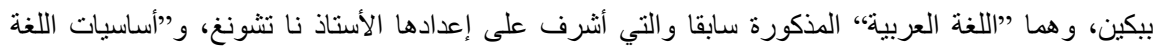

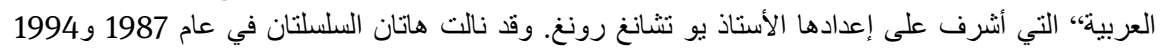

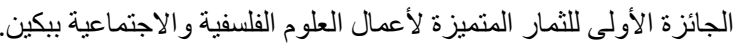

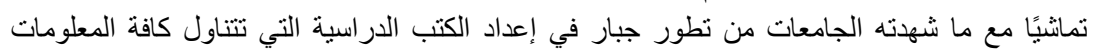

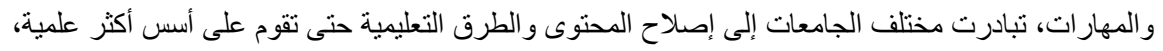

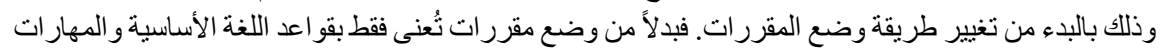

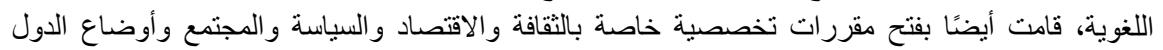

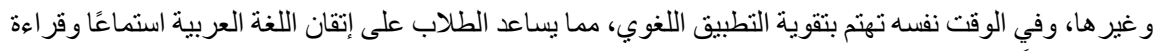

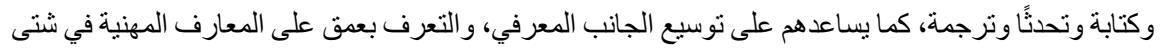

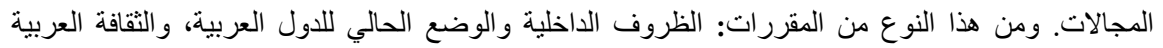

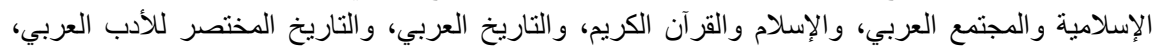

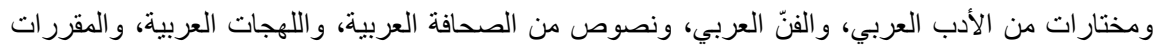

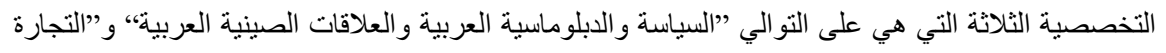

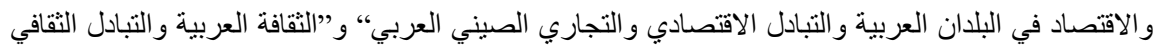

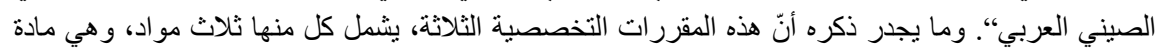


اللمحة النظرية ومادتا الترجمة التحريرية و الترجمة الثفوية. وتدرّس مادة اللمحة النظرية باللغة العربية، حيث تم

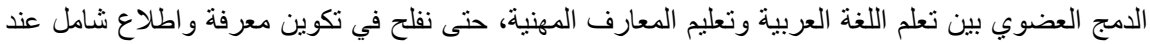

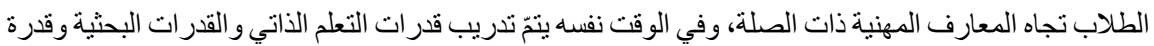

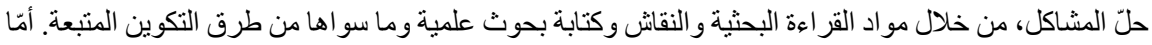

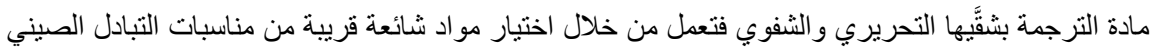

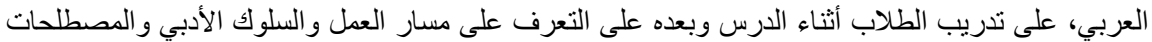

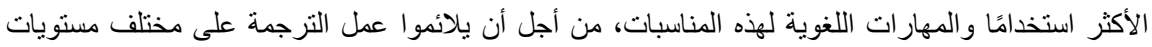

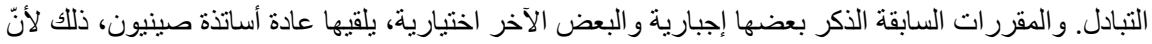

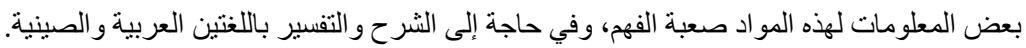

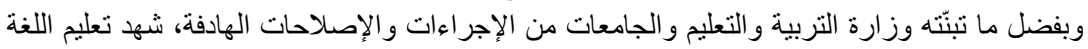

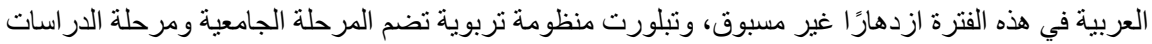

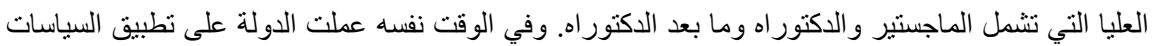

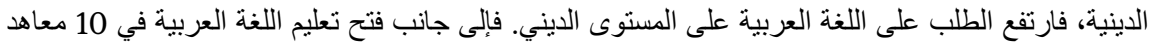

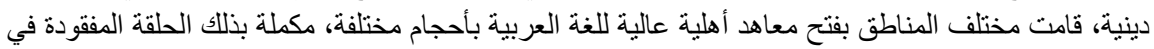

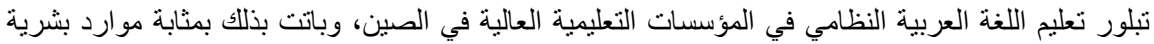
تستحق العناية والتطوير و الاستغلال في مجال تعليم اللغة العربية في الصين.

\section{5 فترة السعي إلى التميز: من 2004 حتى الآن}

في مطلع القرن الـ21، وفي ظلّ موجة التعددية القطبية العالمية و العولمة الاقتصادية، شهد الوضع السياسي الدولي

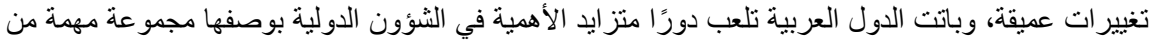

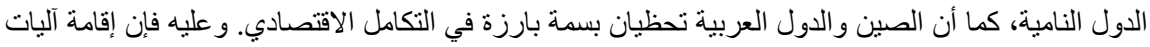

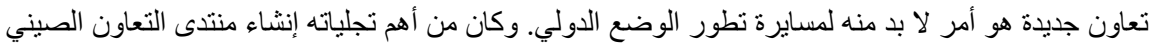

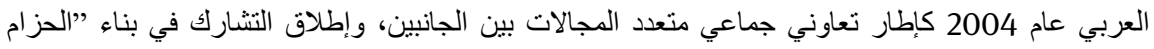

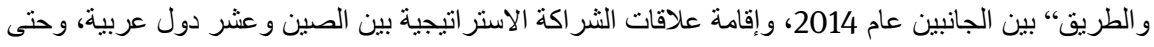

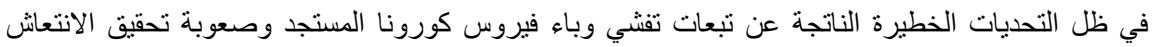

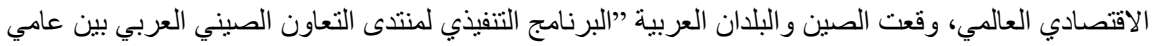

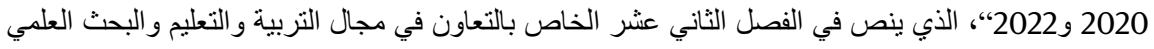

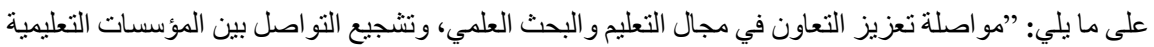

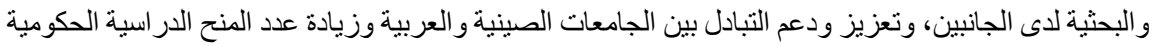

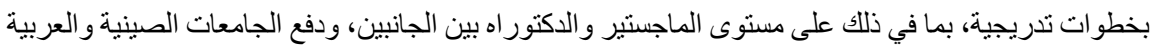

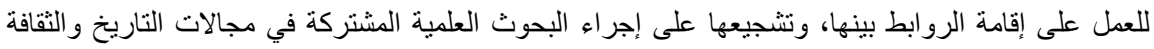

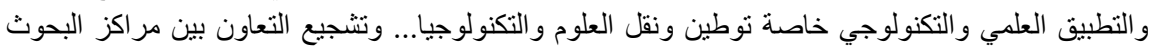

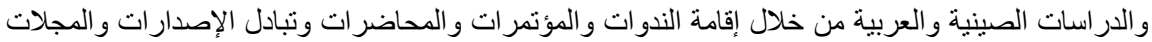

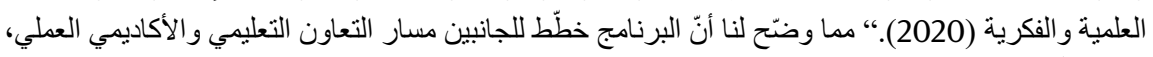

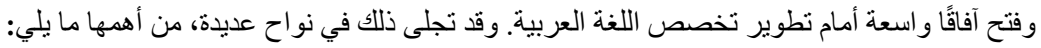




\section{5 مقاعد القبول للطلبة تثنه زيادة سريعة، وآفاق توظيف الخريجين تبعث على التفاؤل}

قبل إنشاء منتدى التعاون الصيني العربي عام 2004، فتحت 13 جامعة تخصص اللغة العربية و آدابها. أما بعد ذلك الكي

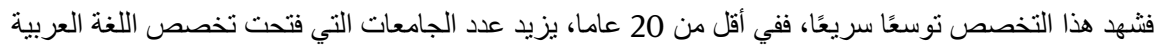

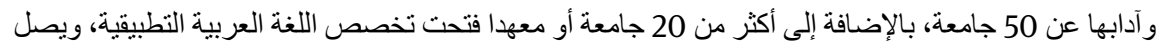

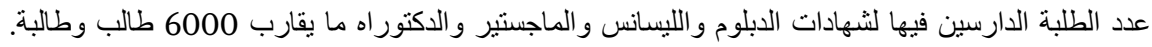

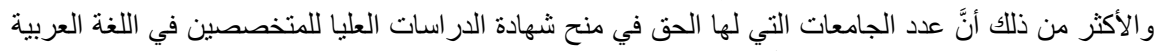

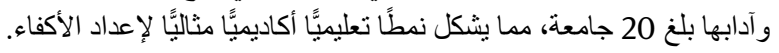

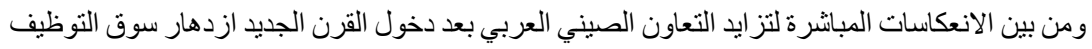

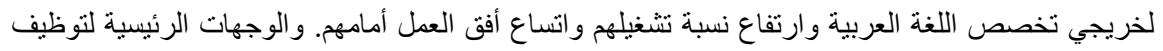

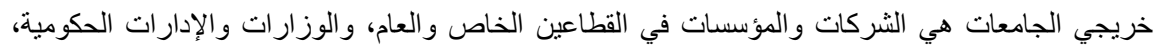

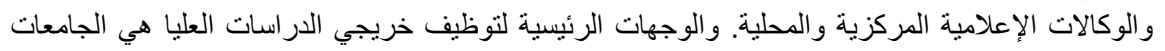

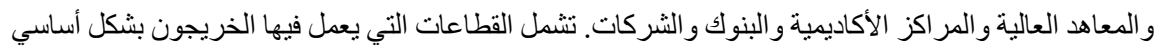

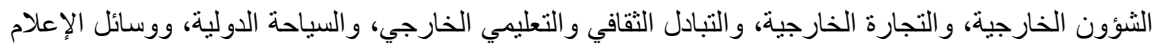

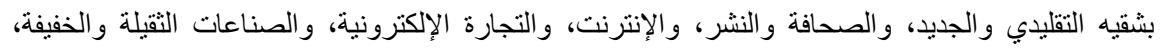
و التكنولوجيا الإلكترونية، و إلخ.

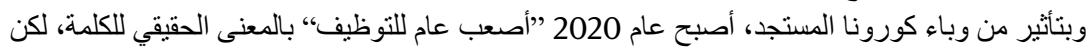

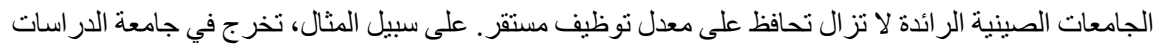

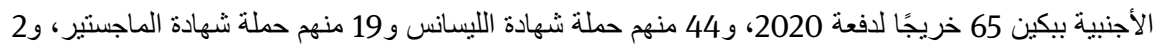

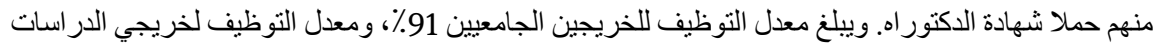

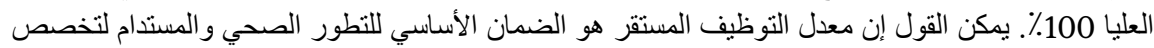
اللغة العربية.

\section{5 إصلاح نمط التكوين لتحسين جودة التعليم}

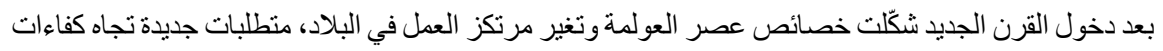

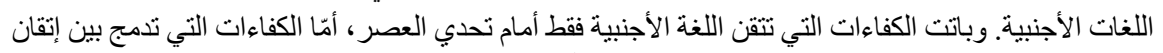

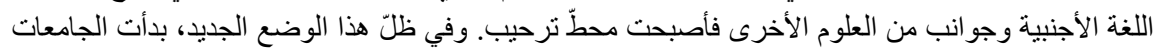

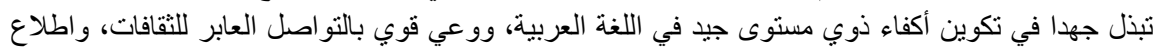

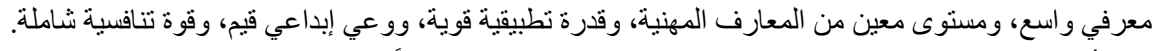

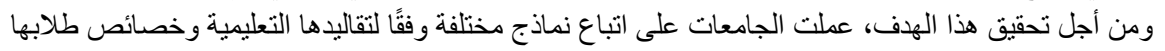

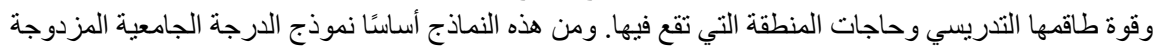

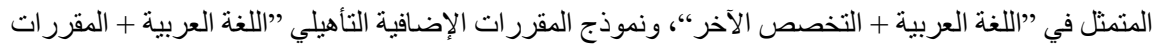

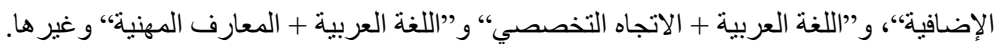

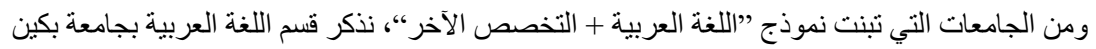

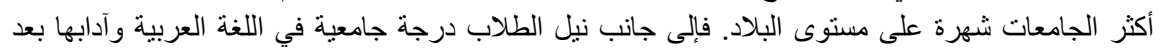

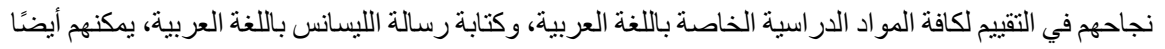

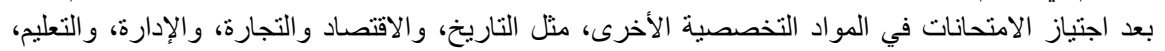

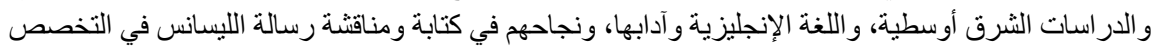


المختار، نيل الشهادة المقابلة لذلك و المعتمدة من قبل وزارة التربية والتعليم الصينية.

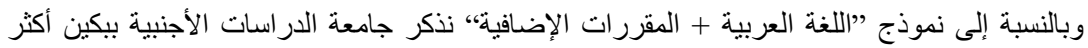

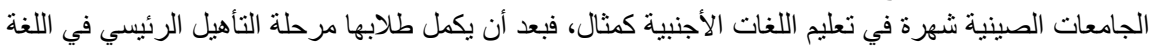

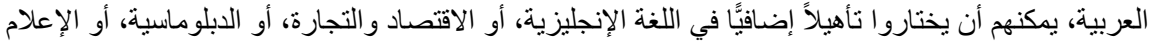

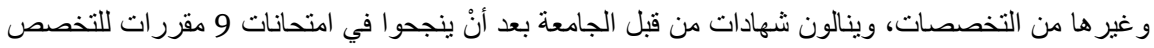
المختار.

أمّا نموذج ”اللغة العربية + اتجاه التخصص“، فقد تبنته على سبيل المثال جامعة الاقتصاد و التجارة الدولية.

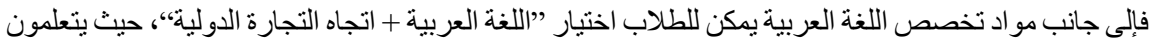

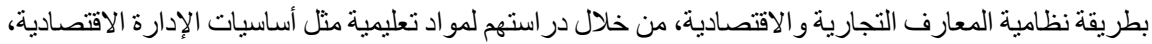

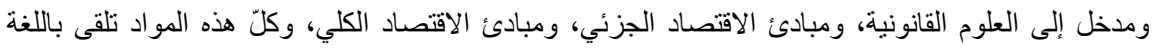

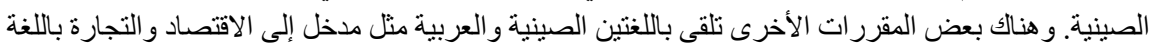

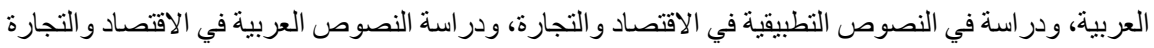
و التفاوض باللغة العربية في الاقتصاد و التجارة.

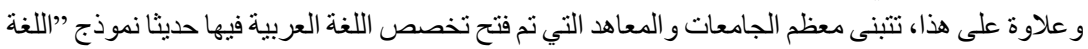

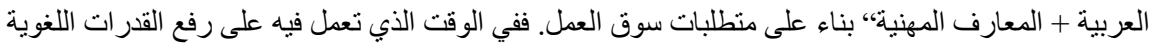

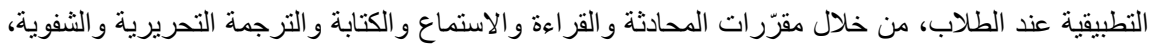

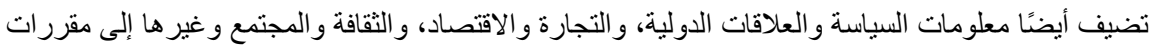

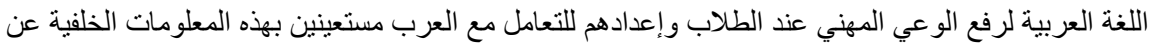

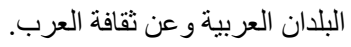

ومن جهة أخرى ظلّت الجامعات نولي عناية خاصة بمشاركة الطلاب في النشاطات الاجتماعية الميدانية،

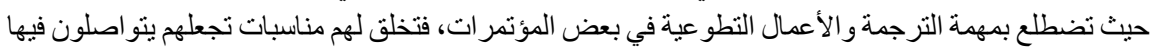

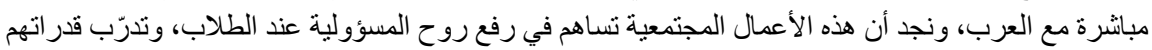

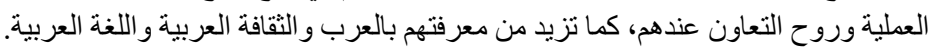

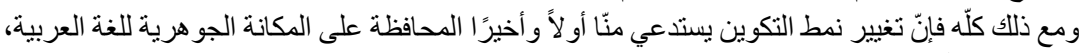

و القيام بإصلاح متعلّق بالمحتوى التعليمي لرفع كفاءة التعليه.

\section{5 تأليف سلسلات من الكتب الدراسية الجديدة وفق تطور المطالب}

تز امنًا مع إصلاح نمط التكوين للجامعيين وتتفيذًا للمطالب الجديدة المطروحة على إثر ذللك، رأى أساتذة تخصص التص

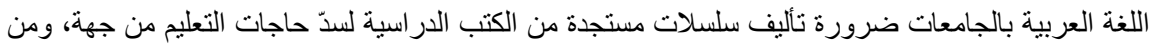

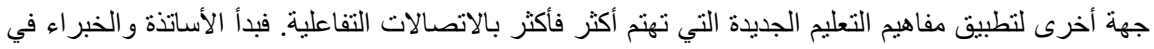

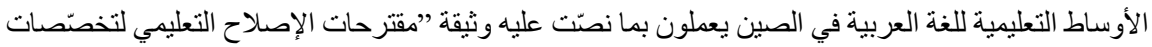

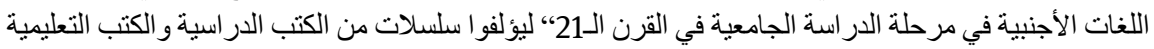

المرجعية.

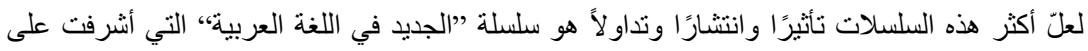

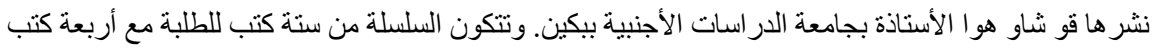

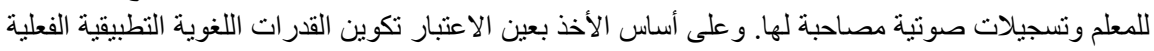

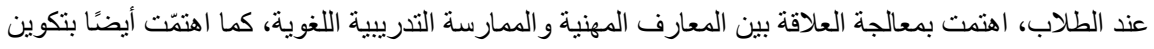

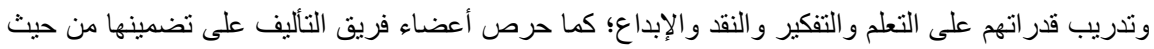


المحتوى ما يساعد على رفع المؤهلات الأخلاقية و التقافية و النفسية و الفكرية للطلاب عن طريق الاختيار الدقيق

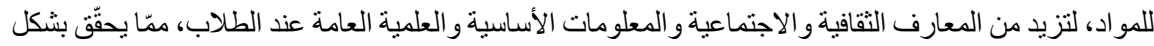

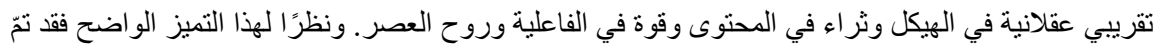

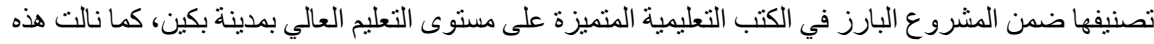

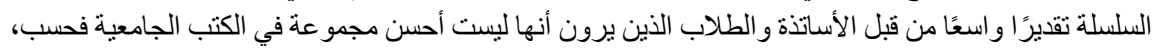

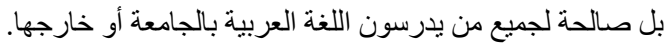

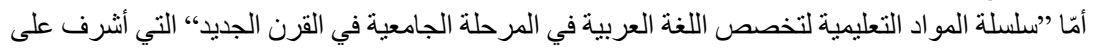

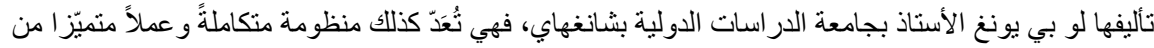

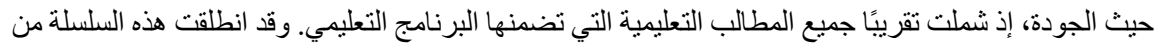

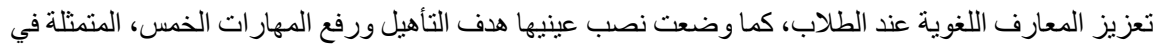

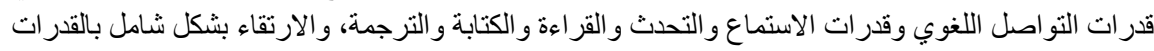

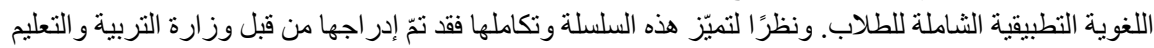

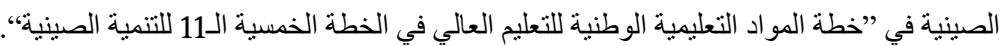

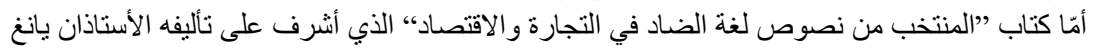

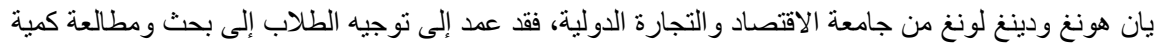

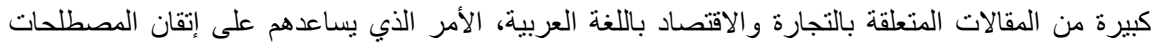

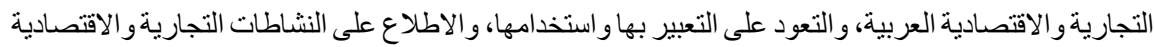
العربية. وقد تم اختيار هذا المرجع التعليمي في عام 2004 ضمن أحد مر اجع التعليم العالي المتميزة في مدينة بكين.

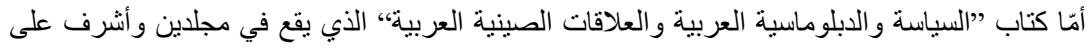

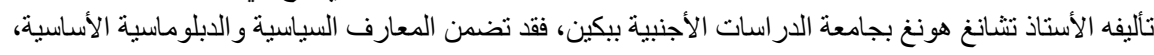

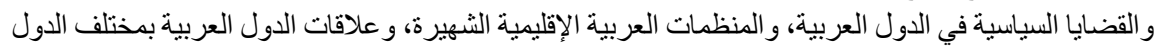

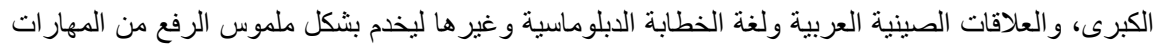

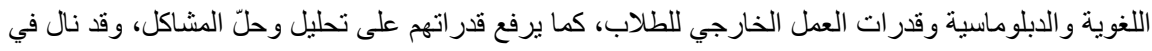

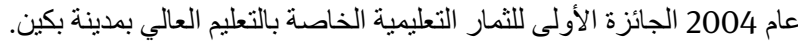

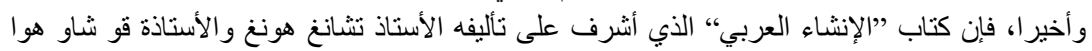

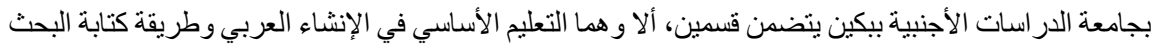

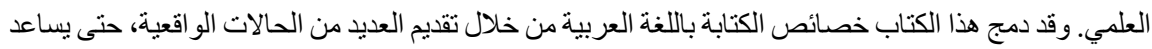

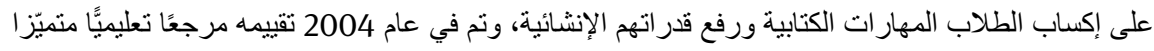
للتعليم العالي في مدينة بكين. تعتبر الكتب الدر اسية حلقة مهمة من عملية التعليم والتعلم، وأداة من أدوات التوجيه التعليمي، وركيزة أساسية

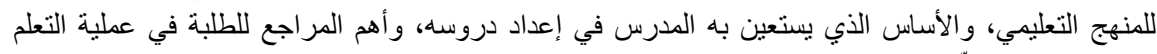

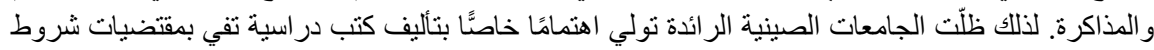

التعليم الجيد.

\section{5 إنجازات مثمرة في التبادلات الخارجية والبحوث الأكاديمية}

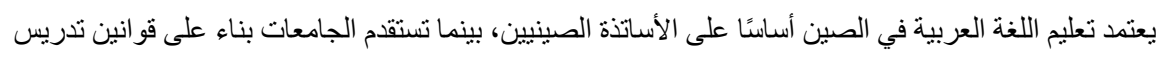

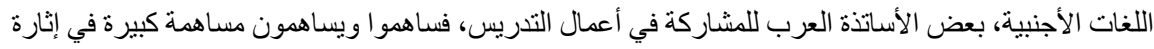
رغبة ودافعية الطلاب إلى تعلم هذه اللغة، و الرقي بمستوى التعليم، كما توفد الجامعات سنويًّا عددًا من الطلبة ـ على فلى اللى 
حساب الحكومة أو على حساب الطلاب ـ للار اسة في الدول العربية، حتى تتاح لهم فرصة التعرف على ألى أحوال

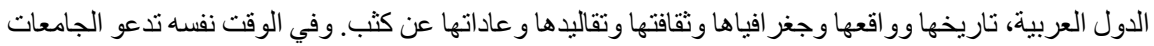

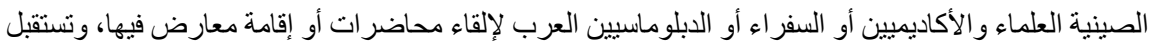

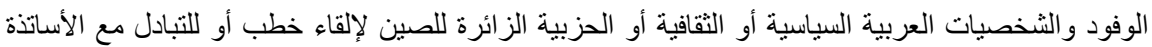

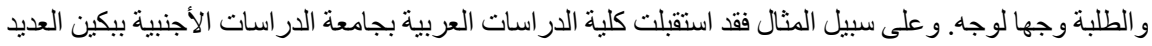

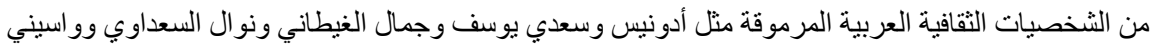

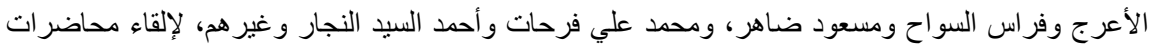

علمية.

إلى جانب ذللك، أقامت الجامعات الصينية الر ائدة التي تدرس فيها اللغة العربية وعلومها علاقات التبادل

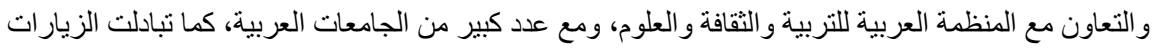

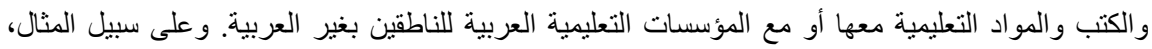

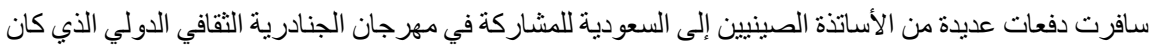

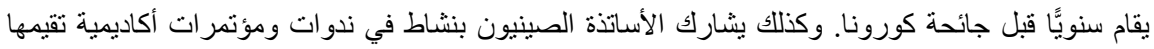

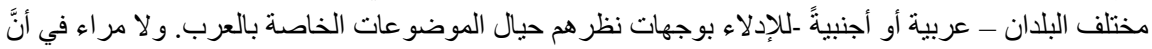

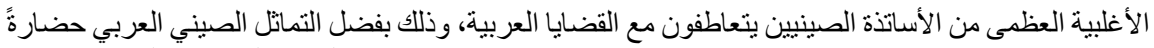

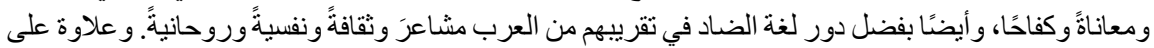

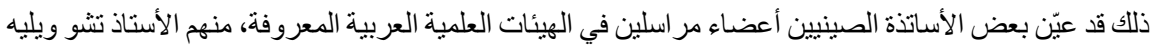

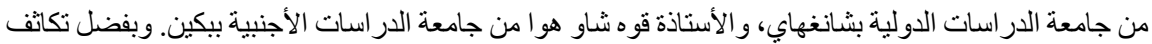

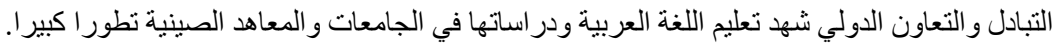

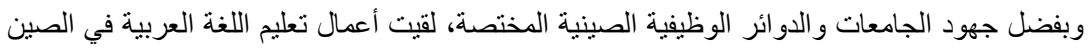

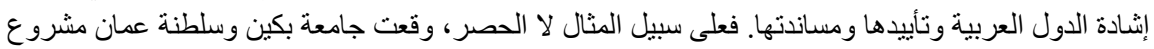

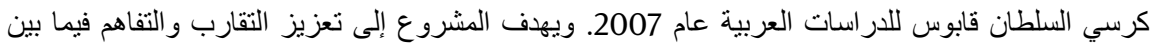

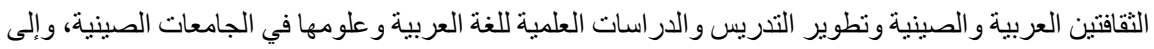

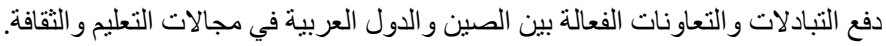

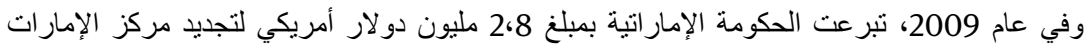

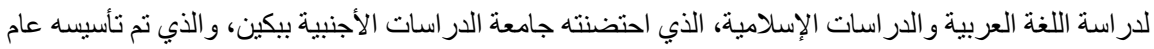

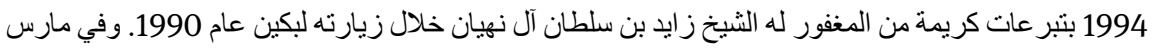

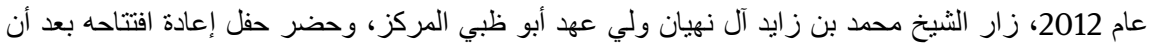

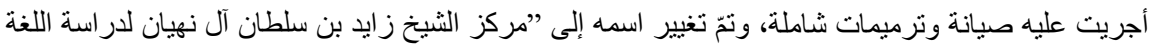

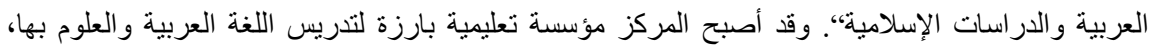

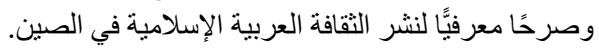

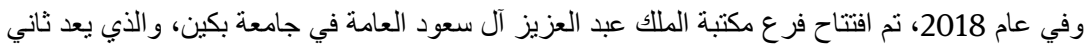

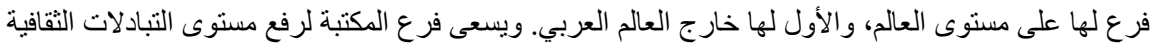

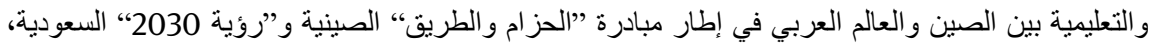

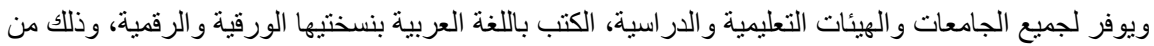

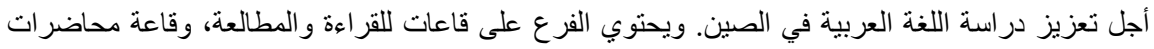

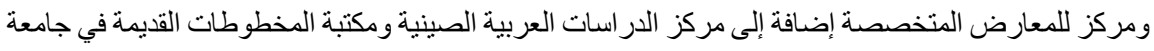

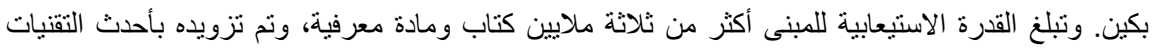

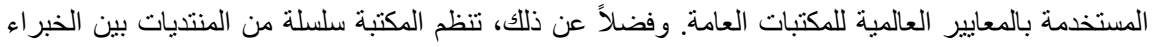
و العلماء الصينيين و العرب، وترجمة الكتب العربية والصينية، ونشر مجلات باللغنتين الصينية لعنية والعربية. 
إلى جانب تعليم اللغة العربية، بذل وما يزال يبذل نخبة من الأساتذة الصينيين جهودا جبارة ودؤوبة في

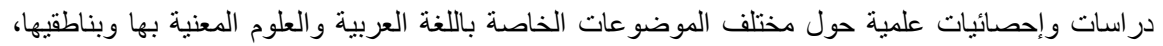

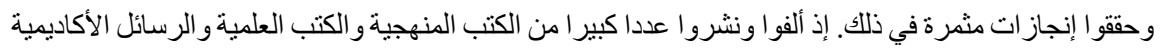

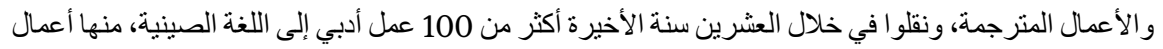

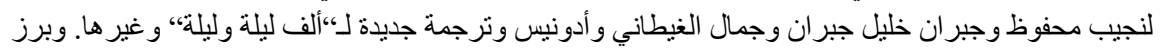

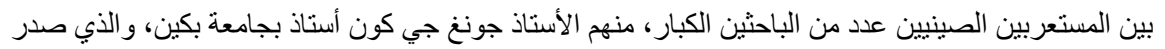

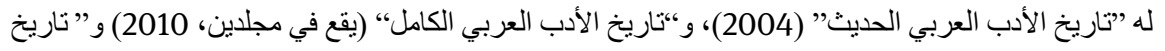

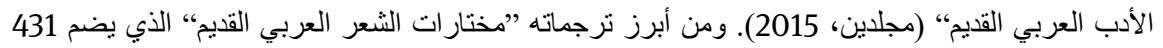

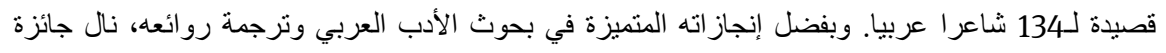

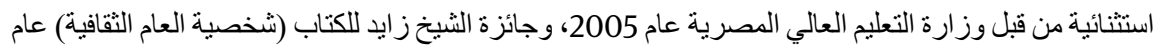

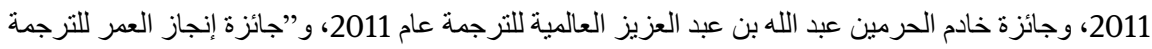
و الثقافة،" عام 2011، وجئرة وادم التي تعد الوسام الأعلى في مجال الترجمة في الصين.

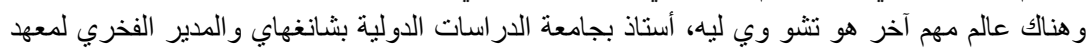

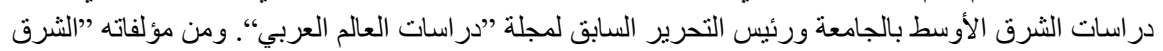

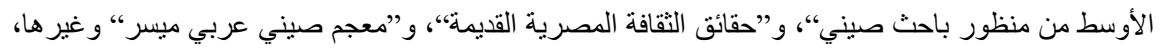

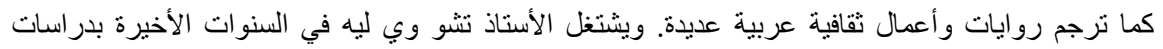

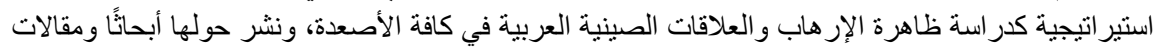

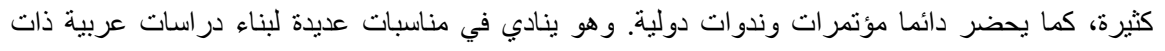

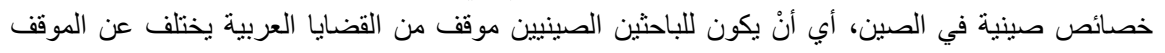
الاستشر اقي الغربي (شوي تشينغ قوه، 2006).

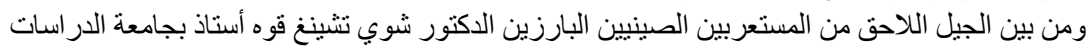

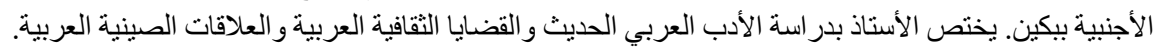

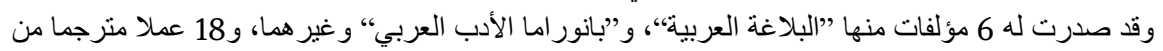

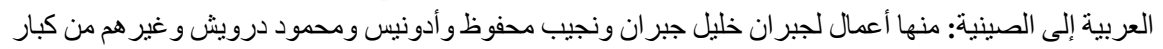

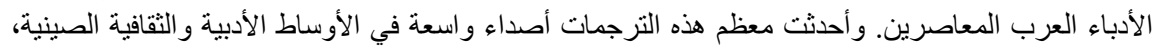

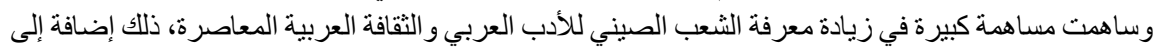

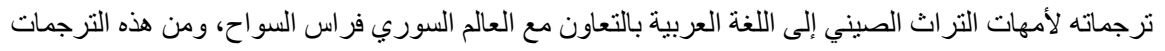

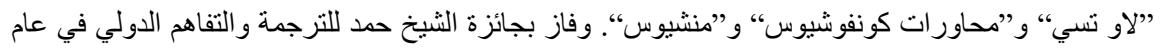

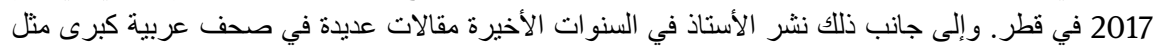

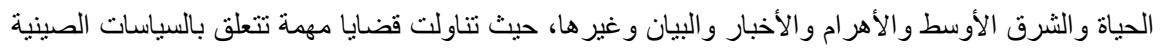

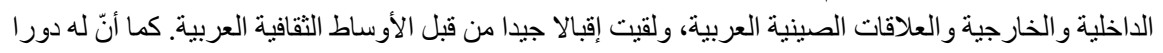

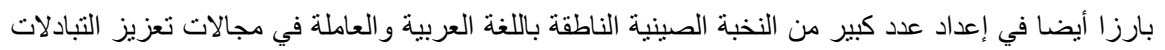
الصبينية العربية.

\section{6 مستقبل تعليم العربية في الجامعات الصينية ـ الفرص والتحديات}

بعد تأسبس الصين الجديدة، حقق تعليم اللغة العربية في الصين بفضل جهود بذلتها أجيال متعاقبة من المستعربين

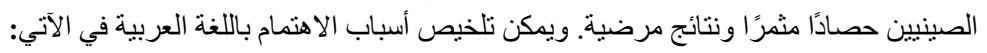

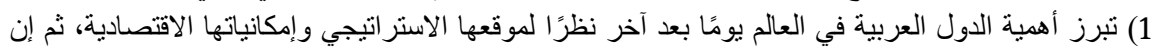


الزخم المستقبلي المتمثل في الأفق الرحب والإمكانيات الهائلة لتعميق التطوير الثامل للعلاقات الصينية العربية،

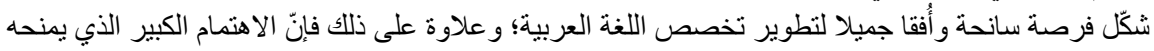

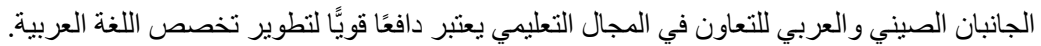

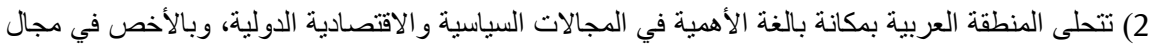

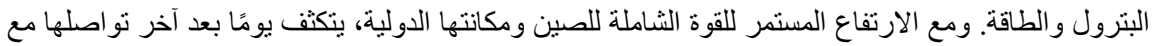

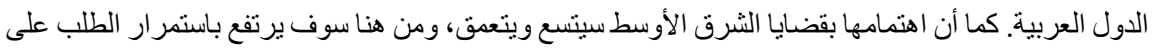

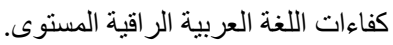

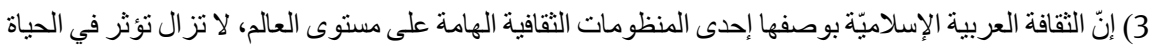

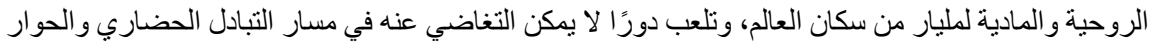

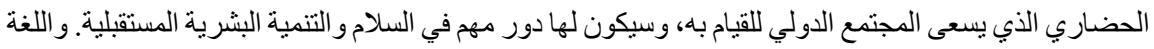

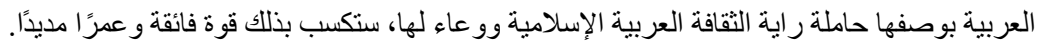

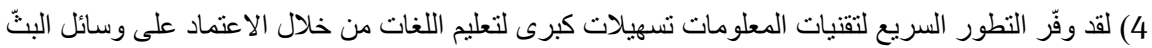

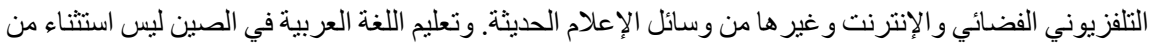

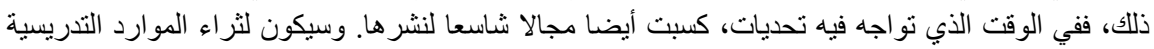

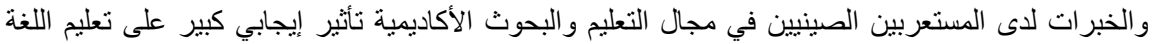
العربية.

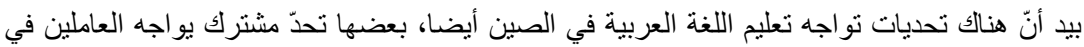

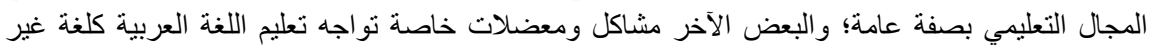

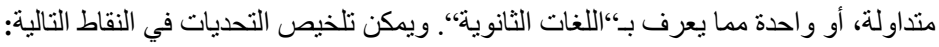

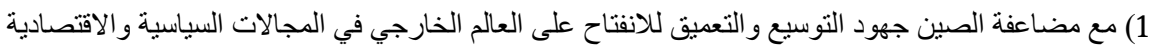

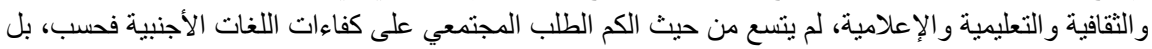

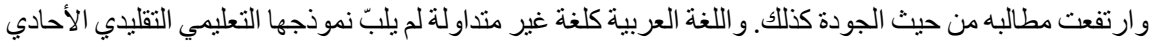

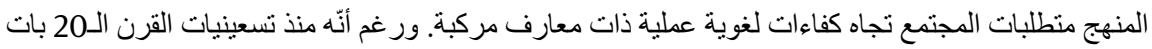

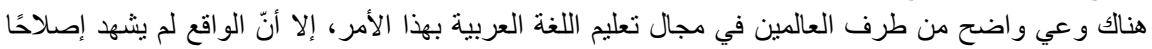

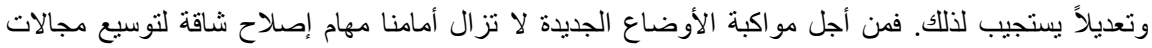

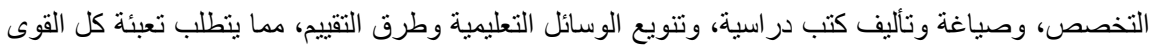
و الموارد في تعليم اللغة العربية في الصين.

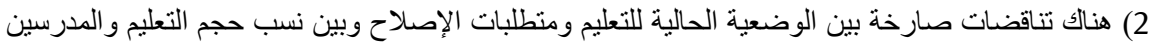

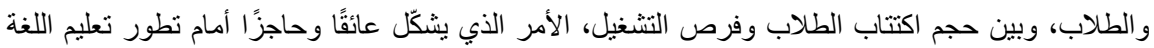

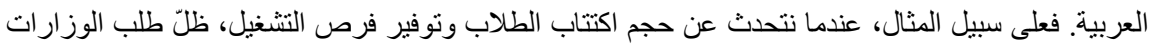

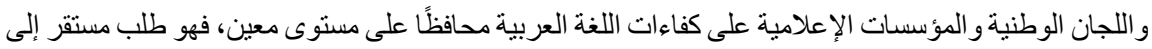

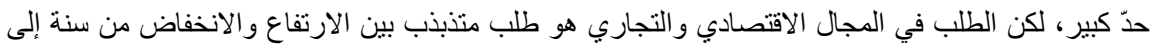

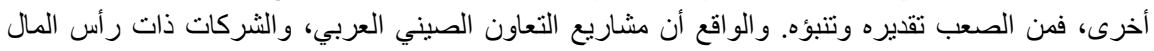

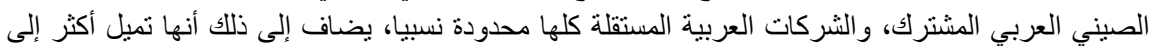

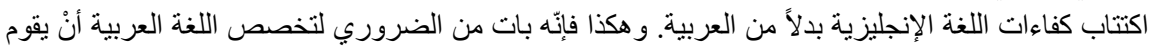

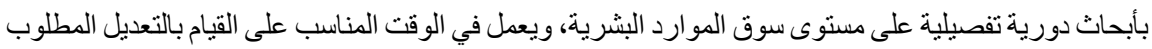

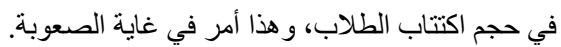

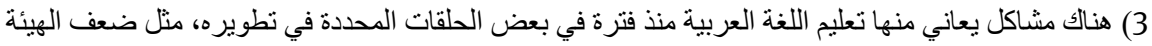

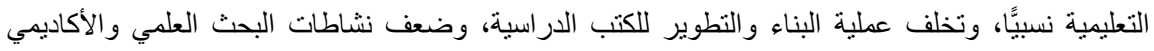

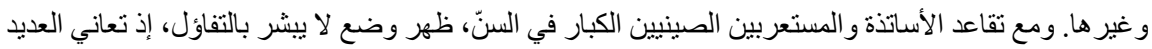


من تخصصات اللغة العربية من النقص في أعضاء الهيئة التعليمية والفريق الأكاديمي؛ ثم إن الأعمال المتعلقة

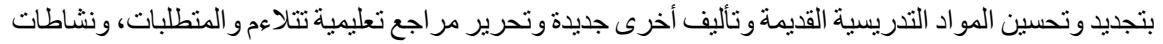

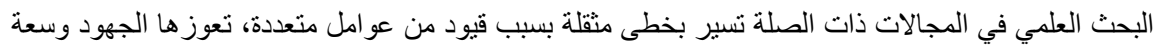
الباع.

ويختار معظم المدرسين الأدب العربي والثقافة الإسلامية والفكر العربي المعاصر وقضايا الثرق الأوسط

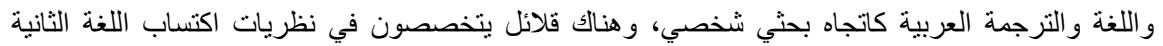

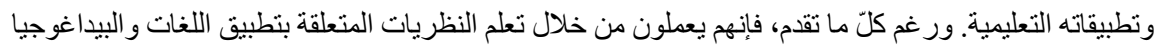

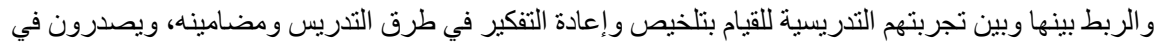
كل عام رسائل علمية متعلقة بالتعليم.

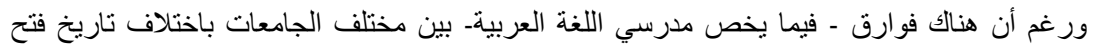

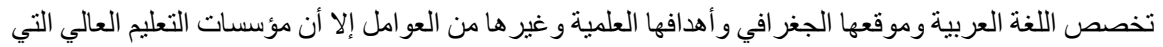

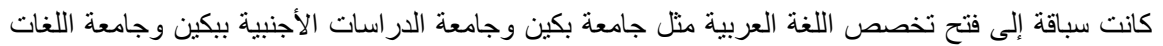

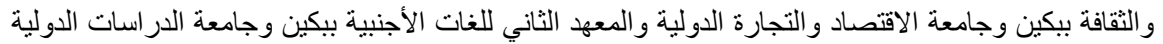

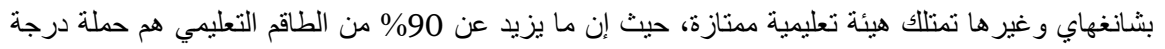

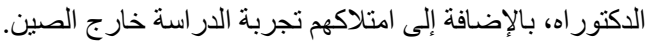

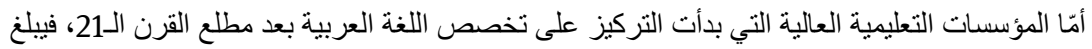

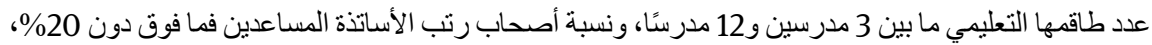

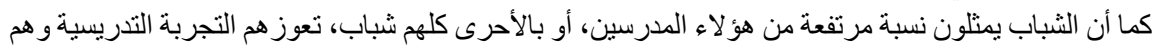

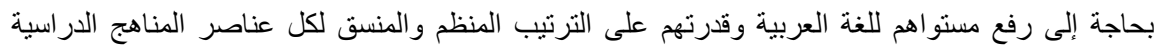

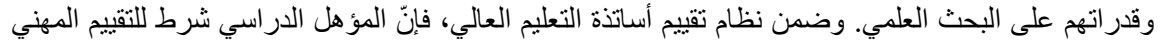

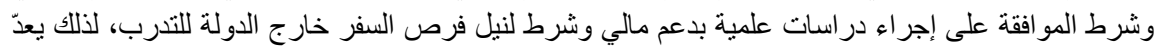

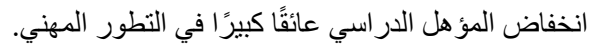

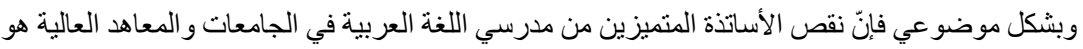

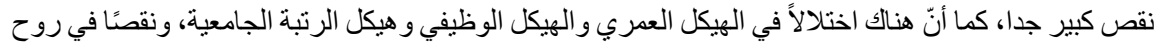
المسؤولية و المستوى المهني عند بعض المدرسين، و هذه كلّها مسائل تتطلب الحل العل العاجل.

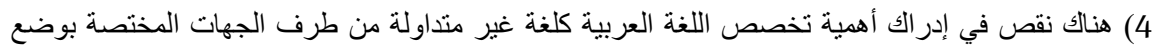

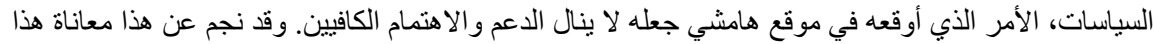

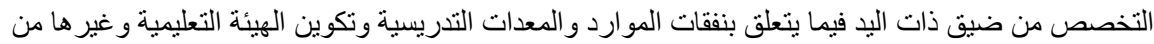

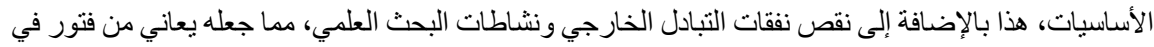
القوة التنموية.

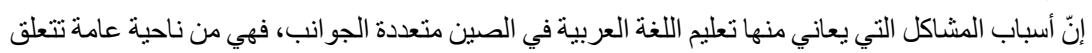

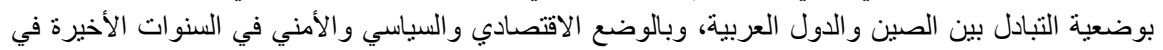

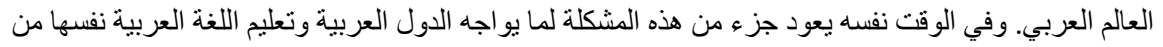

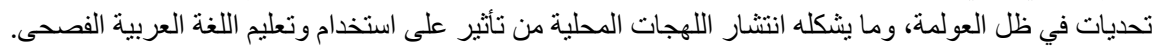

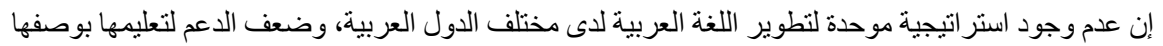

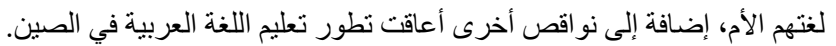

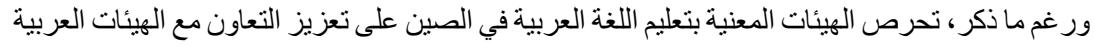

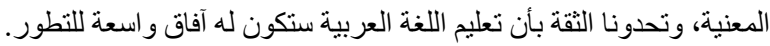




\section{7 الخاتمة}

إنّ تعليم اللغة العربية في الصين شأنه شأن تطور العلاقات العربية الصينية الممتدة، حيث يتحلى بتاريخه الطويل،

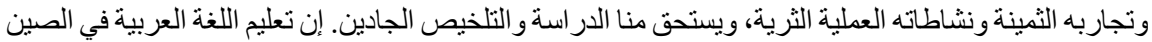

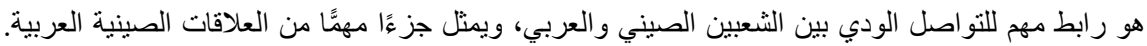

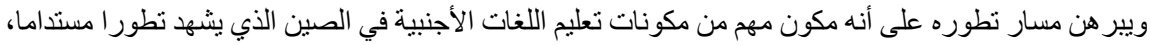
ويرتبط ارتباطا وثيقا بتقدم وازدهار البلاد.

\section{المراجع}

دينغ جيون، (2006). الخطوط العريضة عن تاريخ تعليم اللغة العربية في الصبن. بكين: دار العلوم الاجتماعية الصينية للنشر.

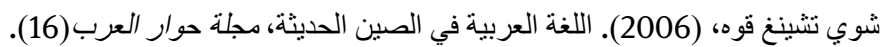

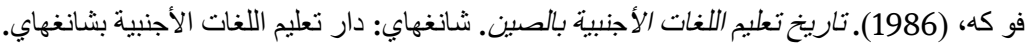

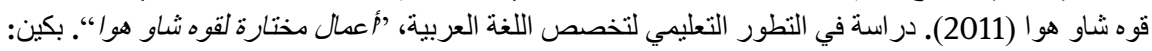
دار التعليم والبحوث في اللغات الأجنبية للنشر.

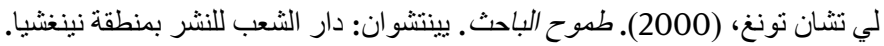
إنشاء و إطلاق عمل لجنة تأليف ومر اجعة الكتب المدرسية للغات الأجنبية في الجامعات و المعاهد العالية، (1980).

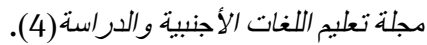

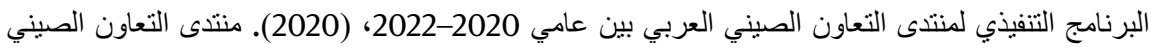
http://www.chinaarabcf.org. العربي 